\title{
Sonic hedgehog pathway mediates genistein inhibition of renal cancer stem cells
}

\author{
ENLAI LI $^{1 *}$, TAO ZHANG ${ }^{1 *}$, XIANCHAO SUN ${ }^{1 *}$, YUAN LI $^{2 *}$, HAO GENG $^{1}$, DEXIN YU $^{1}$ and CAIYUN ZHONG ${ }^{2}$ \\ ${ }^{1}$ Department of Urology, The Second Affiliated Hospital of Anhui Medical University, Hefei, Anhui 230032; \\ ${ }^{2}$ Department of Nutrition and Food Safety, School of Public Health, Nanjing Medical University, \\ Nanjing, Jiangsu 211166, P.R. China
}

Received July 4, 2018; Accepted May 2, 2019

DOI: $10.3892 /$ ol.2019.10657

\begin{abstract}
Cancer stem cells (CSCs) have been implicated in the genesis, progression and recurrence of renal cancer. The sonic hedgehog (Shh) pathway serves a critical role in maintaining the stemness of CSCs. Genistein, a major isoflavone component extracted from soybeans and soy products, has been demonstrated to possess anticancer activity. However, the effects of genistein on renal CSCs and its underlying mechanisms remain to be fully elucidated. The aim of the present study was to investigate the role of the Shh pathway in genistein inhibition of renal CSCs. The results of the present study demonstrated that expression levels of renal CSC markers were markedly upregulated in the sphere-forming cells, which were isolated and enriched from 786-O and ACHN cells in a tumor sphere formation assay, and more cells were arrested at the $G_{0} / G_{1}$ phase instead of the $S_{1}$ phase compared with the adherent cells. Furthermore, the present study demonstrated that genistein could effectively diminish the activity of renal CSCs by suppressing tumor sphere formation, decreasing renal CSCs markers, inhibiting proliferation and inducing apoptosis. Additionally, the downregulation of Shh pathway activity could inhibit renal CSCs. Genistein exhibited an inhibitory effect on renal CSCs by attenuating the activation of the Shh pathway. In conclusion, the results illustrated the role of the Shh pathway in regulating renal CSC traits and the intervention of renal CSCs by genistein, which could
\end{abstract}

Correspondence to: Professor Dexin Yu, Department of Urology, The Second Affiliated Hospital of Anhui Medical University, 80 Feicui Road, Hefei, Anhui 230032, P.R. China

E-mail: ay2fy_uro@126.com

Professor Caiyun Zhong, Department of Nutrition and Food Safety, School of Public Health, Nanjing Medical University, 81 Tianyuan Road, Nanjing, Jiangsu 211166, P.R. China

E-mail: cyzhong@njmu.edu.cn

*Contributed equally

Key words: genistein, renal cancer stem cells, sonic hedgehog pathway, inhibition, renal carcinoma provide novel insights into the molecular mechanisms of renal CSC intervention.

\section{Introduction}

Renal cancer is a deadly disease with a global annual incidence of 143,000 cases of cancer-associated mortality, with the 9th highest incidence rate in men and 14th highest in women, as reported in 2012 (1). Renal cell carcinoma (RCC) is the most common form of renal neoplasm, accounting for $>90 \%$ of cases in adults regardless of sex, worldwide (1). The high metastatic rate of RCC and its resistance to traditional chemotherapy and radiotherapy results in an unpredictable presentation as well as adverse clinical outcomes. Although surgical treatment remains the gold standard for treating primary RCC, 30-40\% patients may undergo progression or recurrence following the initial radical nephrectomy, and the 5 -year survival rate of metastatic patients was only $12 \%$ in 2015 (2). Therefore, there is an urgent need to investigate novel approaches for treating RCC.

Cancer stem cells (CSCs), a minor initiating cell subpopulation within solid tumors, are associated with unique characteristics, including clonogenesis, high self-renewal capacity and multilineage differentiation properties (3). Emerging evidence has demonstrated that CSCs are implicated in tumorigenesis, progression, chemoresistance and relapse of malignancies (3-5). To date, CSCs have been isolated and identified in various types of solid malignancy or established cell lines, including glioblastoma, breast cancer and renal cancer (6-8). Bussolati et al (9) isolated renal CSCs from the tumor samples of patients with clear cell RCC using fluorescence-activated cell sorting in 2008. Subsequently, Zhong et al (10) enriched CSCs from the RCC cell line SK-RC-42 using a sphere-formation assay. In addition, Huang et al (11) identified a cancer stem-like cell side population in the $769 \mathrm{P}$ cell line. Therefore, understanding the biology of renal CSCs for selective targeting can be an effective interventional strategy in preventing and treating renal cancer.

The sonic hedgehog (Shh) pathway has been considered as an oncogenic pathway, serving a crucial role in the maintenance of tissue polarity and CSC properties (12). Aberrant activation of the Shh pathway has been reported to be involved in various 
types of human malignancy (13). The binding of hedgehog ligands, including Shh protein, to the transmembrane receptor patched $1(\mathrm{PTCH})$ results in the activation of the Shh pathway. PTCH represses the activity of the transmembrane protein smoothened (Smo) in the absence of Shh protein, which can thereby activate an endocellular signal transduction cascade via the glioma-associated oncogene (Gli) transcription factor family, including Gli1, Gli2 and Gli3 (14). Gli1 acts as a transcription activator, while Gli2 and Gli3 can function either as repressors or activators depending on the context $(14,15)$.

Recently, numerous studies have illustrated that dietary factors exert chemo-preventative functions and can decrease the risk of multiple types of cancer (16-18). Notably, certain botanical compounds can directly regulate CSC activity; compounds that have now been identified as promising anticancer and therapeutic agents. Among these compounds, genistein (4,5,7-trihydroxyisoflavone), a major isoflavone component that can be isolated from soybeans and soy products, possesses anticancer potential by targeting the CSCs of different tumors $(19,20)$. Genistein exerts anticancer effects on various types of malignancy, including breast, colon and ovarian cancer $(19,21,22)$. Additionally, it has been reported that genistein inhibits the pluripotency of prostate and gastric cancer cells by targeting the hedgehog-Gli1 pathway $(20,23)$.

However, to the best of our knowledge, the anticancer properties of genistein against renal CSCs remain to be elucidated. Therefore, the aim of the present study was to evaluate the anticancer effects of genistein on renal CSCs, and to evaluate whether the Shh pathway may be involved in the genistein-induced anticancer activity. The findings of the present study may provide valuable avenues in the search for a potential interventional target of genistein in renal CSCs.

\section{Materials and methods}

Chemicals and reagents. Genistein and DMSO were purchased from Sigma-Aldrich; Merck KGaA. Vismodegib and purmorphamine were purchased from MedChemExpress and dissolved in DMSO at a stock solution concentration of $10 \mathrm{mM}$. Epidermal growth factor (EGF), basic fibroblast growth factor (bFGF) and insulin were purchased from PeproTech, Inc.. In addition, 2\% B27 was acquired from Gibco; Thermo Fisher Scientific, Inc..

The primary antibodies that were used in the present study, including Shh (cat. no. 20697-1-AP), Gli1 (cat. no. 66905-1-Ig), Gli2 (cat. no. 18989-1-AP), CD44 (cat. no. 15675-1-AP), CD133 (cat. no. 18470-1-AP), aldehyde dehydrogenase 1 family member A1 (ALDH1A1) (cat. no. 15910-1-AP), Oct4 (cat. no. 11263-1-AP), Nanog (cat. no. 14295-1-AP), cyclin D1 (cat. no. 60186-1-Ig), proliferating cell nuclear antigen (PCNA) (cat. no. 10205-2-AP), Bcl-2 (cat. no. 12789-1-AP), Bax (cat. no. 50599-2-Ig), and GAPDH (cat. no. 10494-1-AP) were purchased from ProteinTech, Inc.. Cleaved caspase 3 (cat. no. 9661), cleaved caspase 8 (cat. no. 8592) and cleaved caspase 9 (cat. no. 20750) were obtained from Cell Signaling Technology, Inc.. Smo (cat. no. DF5152) was obtained from Affinity Biosciences, Inc. Anti-rabbit (cat. no. SA00001-2) and anti-mouse (cat. no. SA00001-1) second antibodies were purchased from ProteinTech, Inc..
Cell culture and sphere formation assay. The renal cancer 786-O and ACHN cell lines were purchased from Type Culture Collection of the Chinese Academy of Sciences and cultured in RPMI-1640 medium (Gibco; Thermo Fisher Scientific, Inc.) supplemented with 10\% FBS (Gibco; Thermo Fisher Scientific, Inc.), $100 \mathrm{IU} / \mathrm{ml}$ penicillin and $100 \mu \mathrm{g} / \mathrm{ml}$ streptomycin. All cells were cultured at $37^{\circ} \mathrm{C}$ with $5 \% \mathrm{CO}_{2}$.

The 786-O and ACHN cells were washed twice, seeded into a low-attachment plate at a density of 5,000 cells/well, and cultured at $37^{\circ} \mathrm{C}$ in a humidified incubator with $5 \% \mathrm{CO}_{2}$ in serum-free DMEM/F12 (Gibco; Thermo Fisher Scientific, Inc.) containing $4 \mathrm{mg} / \mathrm{ml}$ insulin, $20 \mathrm{ng} / \mathrm{ml} \mathrm{EGF,} 20 \mathrm{ng} / \mathrm{ml}$ bFGF, B27 (1:50 dilution) and 0.4\% BSA (Beyotime Institute of Biotechnology). Half fresh medium was renewed and chemicals (genistein, vismodegib or purmorphamine) were added every other day. Tumor sphere formation was observed and images were captured using a light microscope (Nikon Corporation).

To investigate the effect of genistein and purmorphamine on the tumorsphere formation capacity of renal CSCs, various concentrations of genistein $(0,30,60$ and $90 \mu \mathrm{M})$ or purmorphamine $(1 \mu \mathrm{M})$ were added to each well with $0.1 \%$ DMSO as the control. After 5 days treatment at $37^{\circ} \mathrm{C}$ in a humidified incubator with $5 \% \mathrm{CO}_{2}$, the number of tumor spheres in each group with a diameter $>50 \mu \mathrm{m}$ was counted.

Cell cycle analysis. Following culture in serum-supplemented medium (SSM) or serum-free medium (SFM) for 5 days, 786-O and ACHN cells were collected at a density of $1 \times 10^{6} / \mathrm{ml}$, and then fixed with $75 \%$ ice-cold ethanol at $-20^{\circ} \mathrm{C}$ overnight. Subsequently, the cells were washed twice with PBS and treated with $20 \mathrm{mg} / \mathrm{ml}$ propidium iodide (PI; Invitrogen; Thermo Fisher Scientific, Inc.), 0.1\% Triton X-100 (Invitrogen; Thermo Fisher Scientific, Inc.) and $0.2 \mathrm{mg} / \mathrm{ml}$ RNase (PureLink; Thermo Fisher Scientific, Inc.) at room temperature in the dark for $15 \mathrm{~min}$. Subsequently, flow cytometry (FCM) using a FACSCalibur $^{\mathrm{TM}}$ flow cytometer (BD Biosciences) was used to analyze the cell cycle phase distribution and the percentage of cells in different phases. The data were analyzed using FlowJo software (v10.0.7; FlowJo LLC).

Western blotting. 786-O and ACHN tumor spheres were harvested and washed with ice-cold PBS. The cell precipitates were homogenized in RIPA buffer (Beyotime Institute of Biotechnology) containing complete protease inhibitors, followed by centrifugation at $15,000 \mathrm{x}$ g for $30 \mathrm{~min}$ at $4{ }^{\circ} \mathrm{C}$. The supernatants were collected and denatured. BCA protein assay (Pierce; Thermo Fisher Scientific, Inc.) was utilized to determine the concentration of each protein. The proteins (50 $\mu \mathrm{g}$ per lane) were separated via 10\% SDS-PAGE and then transferred onto PVDF membranes (EMD Millipore). Subsequently, the PVDF membranes were treated with 5\% skimmed milk at room temperature for $2 \mathrm{~h}$ and incubated with the primary antibodies against CD133 (1:500 dilution), Gli1 (1:500 dilution), Gli2 (1:500 dilution), CD44 (1:1,000 dilution), ALDH1A1 (1:1,000 dilution), CD44 (1:1,000 dilution), Oct4 (1:1,000 dilution), Nanog (1:1,000 dilution), Bcl2 (1:1,000 dilution), Bax (1:1,000 dilution), cleaved caspase 3 (1:1,000 dilution), cleaved caspase 9 (1:1,000 dilution), cleaved caspase 8 (1:1,000 dilution), cyclin D1 (1:1,000 dilution), PCNA (1:1,000 dilution), Shh (1:1,000 dilution), Smo (1:1,000 
Table I. Oligonucleotide sequences of primers for reverse transcription-quantitative PCR.

\begin{tabular}{lll}
\hline Genes & \multicolumn{1}{c}{ Forward $\left(5^{\prime}-3^{\prime}\right)$} & \multicolumn{1}{c}{ Reverse $\left(5^{\prime}-3^{\prime}\right)$} \\
\hline CD133 & TACAACGCCAAACCACGACTGT & TCTGAACCAATGGAATTCAAGACCCTTT \\
CD44 & AGCAACCAAGAGGCAAGAAA & GTGTGGTTGAAATGGTGCTG \\
ALDH1A1 & GCACGCCAGACTTACCTGTC & CCTCCTCAGTTGCAGGATTAAAG \\
Oct4 & GACAACAATGAAAATCTTCAGGAGA & TTCTGGCGCCGGTTACAGAACCA \\
Nanog & TTTGTGGGCCTGAAGAAAACT & AGGGCTGTCCTGAATAAGCAG \\
GAPDH & GACTGTGGATGGCCCCTCCGG & AGGTGGAGGAGTGGGTGTCGC
\end{tabular}

ALDH1A1, aldehyde dehydrogenase 1 family member A1.

dilution), and GAPDH (1:1,000 dilution) at $4^{\circ} \mathrm{C}$ overnight. Membranes were rinsed and incubated with the corresponding peroxidase-conjugated secondary antibodies (1:5,000 dilution) for $1 \mathrm{~h}$ at $25^{\circ} \mathrm{C}$. Chemiluminescent detection was performed using an ECL kit (Beyotime Institute of Biotechnology). GAPDH was used as an internal control in order to measure the relative expression of each protein. ImageJ software (v1.46; National Institutes of Health) was used to quantify the protein bands of interest.

RNA extraction and reverse transcription-quantitative $P C R$ $(R T-q P C R)$. Total cellular RNA was extracted from renal cancer adherent or tumor sphere cells using TRIzol ${ }^{\circledR}$ reagent (Invitrogen; Thermo Fisher Scientific, Inc.), and subsequently reverse-transcribed into cDNA using 5X All-In-One RT master mix (Applied Biological Materials, Inc.), according to the manufacturer's protocol, as follows: $25^{\circ} \mathrm{C}$ for $10 \mathrm{~min}, 42^{\circ} \mathrm{C}$ for $15 \mathrm{~min}$ for cDNA synthesis, then $85^{\circ} \mathrm{C}$ for $5 \mathrm{~min}$ followed by chilling on ice. qPCR was performed using the Power SYBR Green Master mix (Applied Biosystems; Thermo Fisher Scientific, Inc.) and a LC96 real-time PCR system. The amplification reactions were as follows: An initial hold step at $95^{\circ} \mathrm{C}$ for $5 \mathrm{~min}$ and 45 cycles of a two-step PCR $\left(95^{\circ} \mathrm{C}\right.$ for $15 \mathrm{sec}, 54^{\circ} \mathrm{C}$ for $30 \mathrm{sec}$ and $72^{\circ} \mathrm{C}$ for $\left.30 \mathrm{sec}\right)$. GAPDH levels were used as normalization controls. Fold changes in gene expression were calculated using a comparative threshold cycle $(\mathrm{Cq})$ method using the formula $2^{-\Delta \Delta \mathrm{CT}}$ (24). The forward and reverse primers used for qPCR are presented in Table I.

Detection of apoptotic cells by FCM. The apoptosis assay was performed using a fluorescein isothiocyanate (FITC)-Annexin-V apoptosis detection kit purchased from BD Biosciences. Following treatment with genistein at different concentrations $(0,30,60$ and $90 \mu \mathrm{M})$ for 5 days at $37^{\circ} \mathrm{C}$ with $5 \%$ $\mathrm{CO}_{2}, 786-\mathrm{O}$ tumor spheres were harvested and washed twice with PBS. Subsequently, cells were resuspended with $100 \mu \mathrm{l}$ binding buffer (BD Biosciences) at a density of $1 \times 10^{6} / \mathrm{ml}$, incubated with Annexin V-fluorescein isothiocyanate $(5 \mu \mathrm{l})$ and PI $(5 \mu \mathrm{l})$ at room temperature in the dark for $15 \mathrm{~min}$, and then detected using FACSCalibur ${ }^{\mathrm{TM}}$ (BD Biosciences) flow cytometer within $1 \mathrm{~h}$. The data were analyzed using FlowJo software (v10.0.7; FlowJo LLC).

Immunofluorescence staining. Following genistein treatment for 5 days at $37^{\circ} \mathrm{C}$ with $5 \% \mathrm{CO}_{2}$, the tumor spheres were washed three times and fixed with $4 \%$ paraformaldehyde for $15 \mathrm{~min}$ at $25^{\circ} \mathrm{C}$. The tumor spheres were subsequently washed three times with PBS-Tween 20 (PBST) then blocked with 5\% BSA (Beyotime Institute of Biotechnology) for $1 \mathrm{~h}$ at $25^{\circ} \mathrm{C}$, following which the tumor spheres were incubated with a rabbit CD44 or Smo (1:100 dilution) antibody at $4^{\circ} \mathrm{C}$ overnight, followed by washing with PBST three times. Subsequently, tumor spheres were stained with $\mathrm{Cy} 3$-conjugated goat anti-rabbit secondary antibody (1:1,000 dilution; cat. no. P0173; Beyotime Institute of Biotechnology) for $2 \mathrm{~h}$ at $25^{\circ} \mathrm{C}$, followed by counterstaining with DAPI for $10 \mathrm{~min}$ at $25^{\circ} \mathrm{C}$. Images were obtained using a fluorescence microscope (Olympus Corporation) at a magnification of $\mathrm{x} 100$.

Statistical analysis. Each experiment was repeated three times independently. A two-tailed Student's t-test was used to analyze the statistical differences between two groups. One-way analysis of variance with Tukey post hoc test was utilized for comparisons among multiple groups. The results are presented as the mean \pm standard deviation. All analyses were performed using SPSS version 11.0 software (SPSS, Inc.). $\mathrm{P}<0.05$ was considered to indicate a statistically significant difference.

\section{Results}

Tumor sphere formation in renal cancer cells through culture in SFM. A number of studies have reported that CSCs have the ability to grow in suspension and to form spheres through culturing under SFM conditions $(10,25,26)$. Therefore, a tumor sphere formation assay via culturing in SFM is an efficient way to isolate and enrich CSCs. In the present study, 786-O and ACHN cell lines were able to form stable cell spheres following culturing in SFM for 5 days (Fig. 1A). To further elucidate the CSC characteristics of the sphere-forming cells, mRNA and protein expression levels of renal CSC markers, including Nanog, Oct4, ALDH1A1, CD44 and CD133, were detected. Following culturing under SFM conditions for 5 days, the mRNA and protein expression levels of CSC markers were markedly upregulated compared with adherent cells cultured under SSM conditions (Fig. 1B and C). Furthermore, FCM analysis of the cell cycle distribution suggested that the sphere-forming cells were primarily arrested at $G_{0} / G_{1}$ phase instead of $S_{1}$ phase, in contrast to the adherent cells (Fig. 1D). These results illustrated the CSC characteristics of the cells cultured under SFM conditions. 


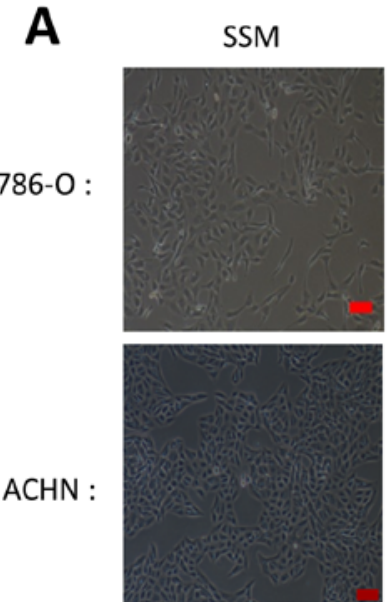

$786-0$

C

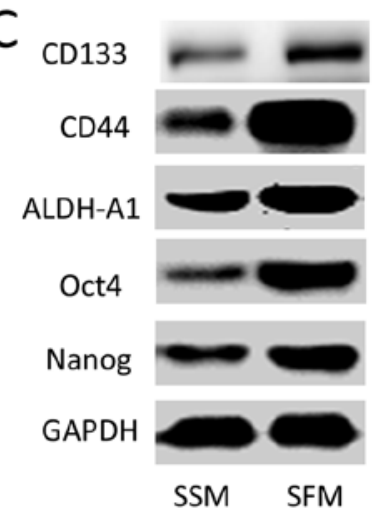

D

786-0:
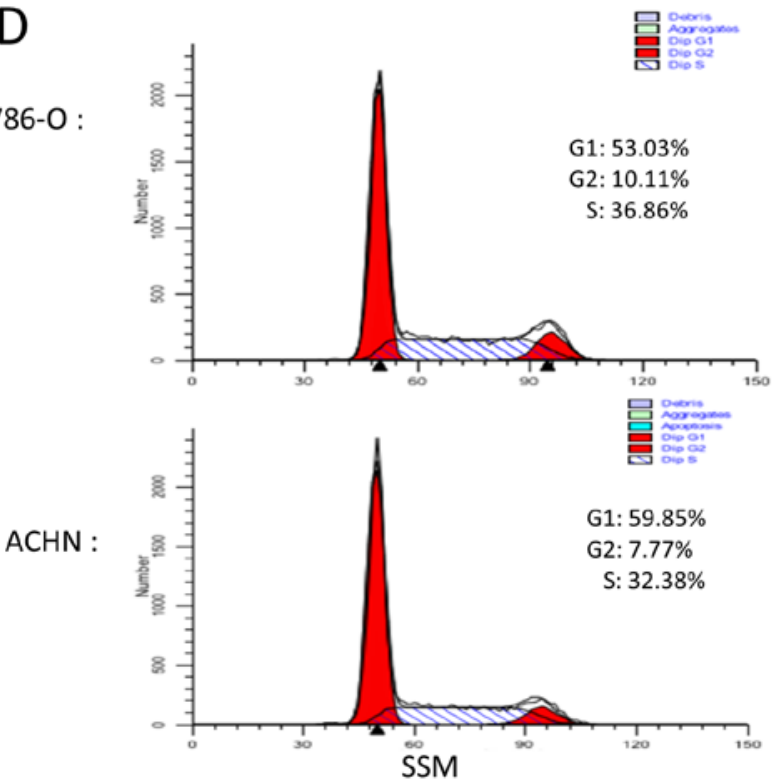

B
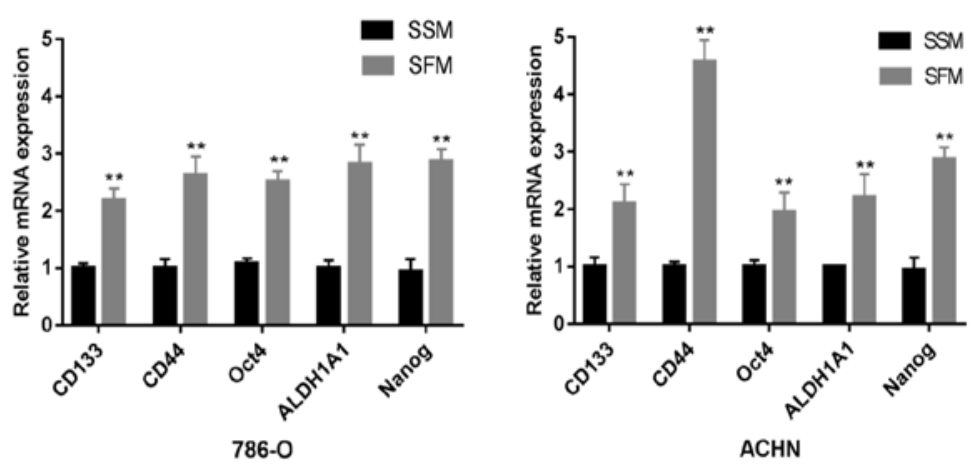

$\mathrm{ACHN}$
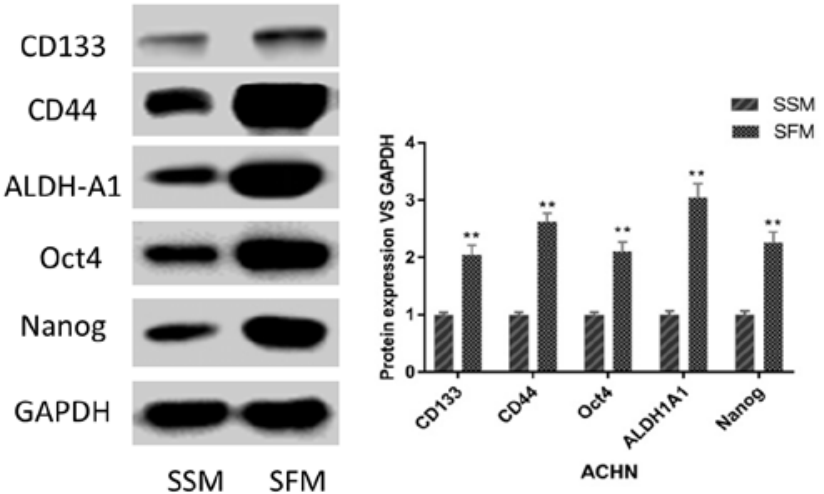

Figure 1. Tumor sphere-formation assay. 786-O and ACHN cells were cultured in SSM and SFM for 5 days. (A) Cell images were captured using a light microscope. Scale bar, $100 \mu \mathrm{m}$. (B) Reverse transcription-quantitative PCR was used to analyze the mRNA levels of renal CSC markers, including CD133, CD44, ALDH1A1, Oct4 and Nanog. (C) Western blotting was used to quantitatively measure the expression levels of corresponding renal CSC markers. (D) Flow cytometry was used to assess cell cycle phase distribution. Data are presented as the mean \pm standard deviation from three independent experiments. ${ }^{* *} \mathrm{P}<0.01$ vs. SSM. ALDH1A1, aldehyde dehydrogenase 1 family member A1; CSC, cancer stem cell; SFM, serum-free medium; SSM, serum-supplemented medium.

Genistein diminishes the characteristics of renal CSCs. Genistein has been demonstrated to target CSCs in several types of malignancy $(20,23,27)$. In the present study, $786-\mathrm{O}$ and ACHN sphere-forming cells were treated with genistein at different concentrations $(0,30,60$ and $90 \mu \mathrm{M})$ for 5 days, in order to investigate whether genistein could exhibit its suppressive effect on renal CSCs. As presented in Fig. 2A and B, the tumor sphere formation assay revealed that genistein-treatment could, in a 


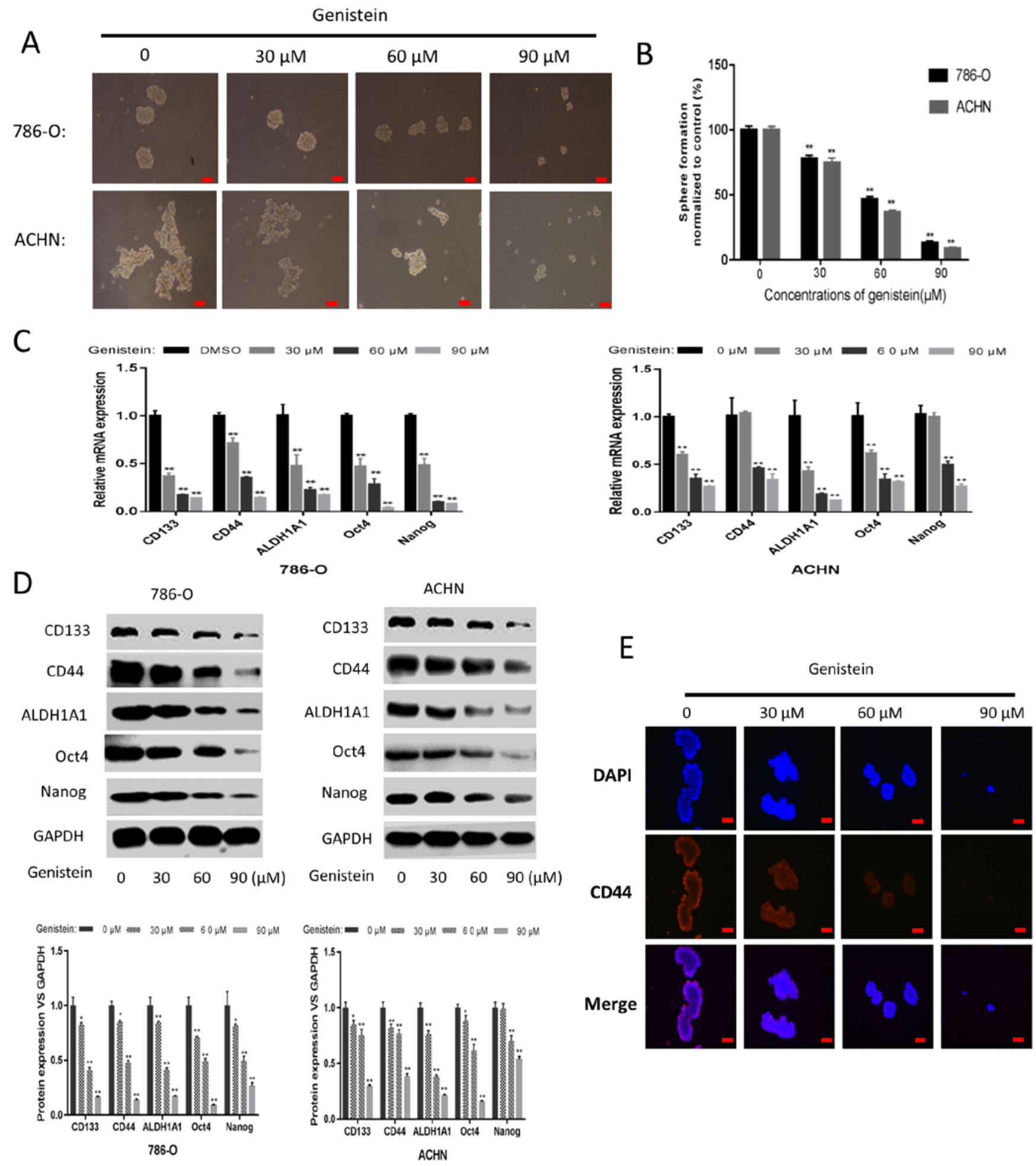

Figure 2. Genistein diminishes renal CSC characteristics. 786-O and ACHN sphere-forming cells were treated with different concentrations of genistein $(0,30,60$ and $90 \mu \mathrm{M})$ for 5 days. (A) Representative images. Scale bar, $100 \mu \mathrm{m}$. (B) Numbers of tumor spheres were counted and normalized to the control group. (C) mRNA expression levels of renal CSC markers were measured by reverse transcription-quantitative PCR. (D) Corresponding protein expression levels of renal CSCs markers were measured by western blotting. (E) Immunofluorescence staining images of 786-O tumor spheres were captured to determine CD44 expression. Scale bar, $100 \mu \mathrm{m}$. Data are presented as the mean \pm standard deviation from three independent experiments. ${ }^{*} \mathrm{P}<0.05$, ${ }^{* * *} \mathrm{P}<0.01 \mathrm{vs}$. genistein $0 \mu \mathrm{M}$. ALDH1A1, aldehyde dehydrogenase 1 family member A1; CSC, cancer stem cell.

dose-dependent manner, significantly reduce the number and size of sphere-forming cells in the two cell lines. Following treatment with genistein for 5 days, the mRNA and protein expression levels of renal CSC markers were markedly downregulated in the sphere-forming cells of the two cell lines (Fig. 2C and D). In addition, immunofluorescent staining indicated that the number of CD44-positive 786-O sphere-forming cells was decreased following genistein treatment in a dose-dependent manner (Fig. 2E). Overall, these data revealed that genistein could effectively diminish the characteristics of renal CSCs. 
A

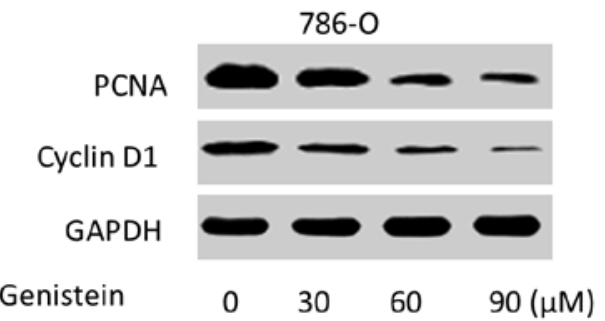

B
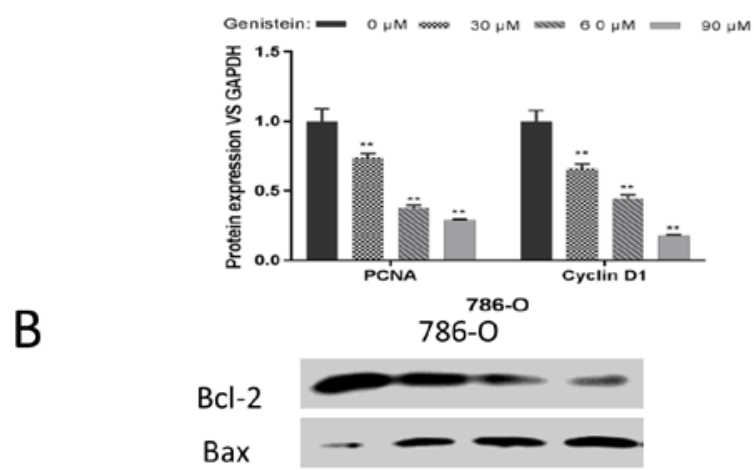

Cleaved Caspase 8

Cleaved Caspase 9

Cleaved Caspase 3

GAPDH

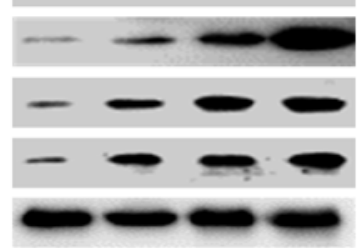

Genistein $\quad 0 \quad 30 \quad 60 \quad 90(\mu \mathrm{M})$

Genistein: $-0 \mu \mathrm{M}=30 \mu \mathrm{M}=00 \% \mathrm{mM}=90 \mu \mathrm{M}$

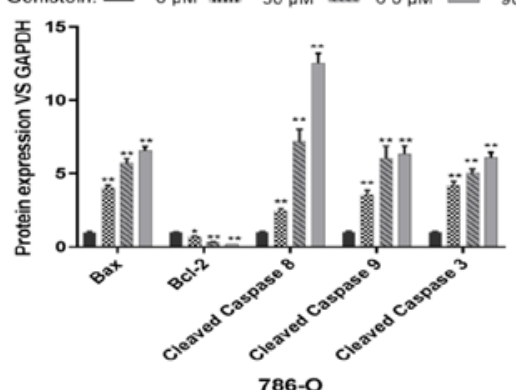

C

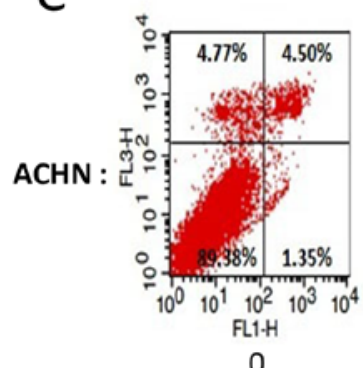

0

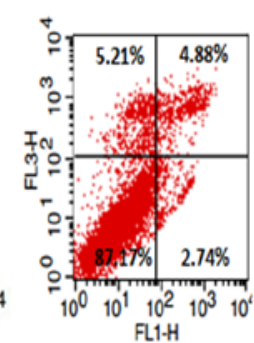

$30 \mu \mathrm{M}$

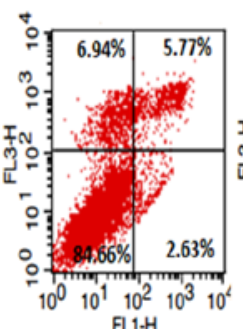

$60 \mu \mathrm{M}$

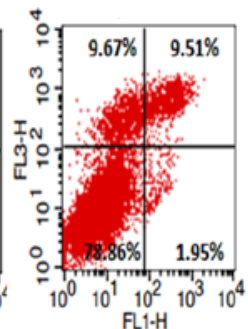

$90 \mu \mathrm{M}$
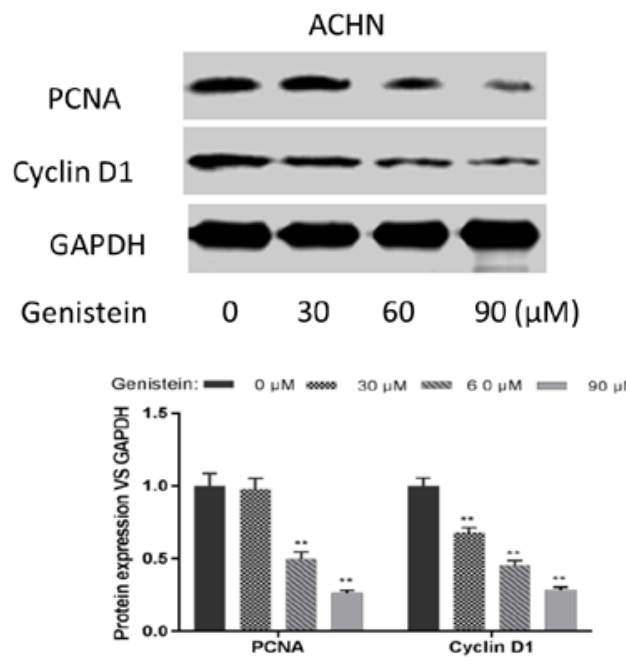

ACHN

$\mathrm{ACHN}$

Bcl-2

Bax

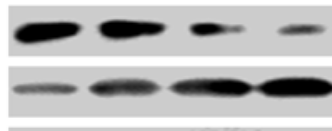

Cleaved Caspase $8-\infty-\infty$

Cleaved Caspase $9+\infty$

Cleaved Caspase 3

GAPDH
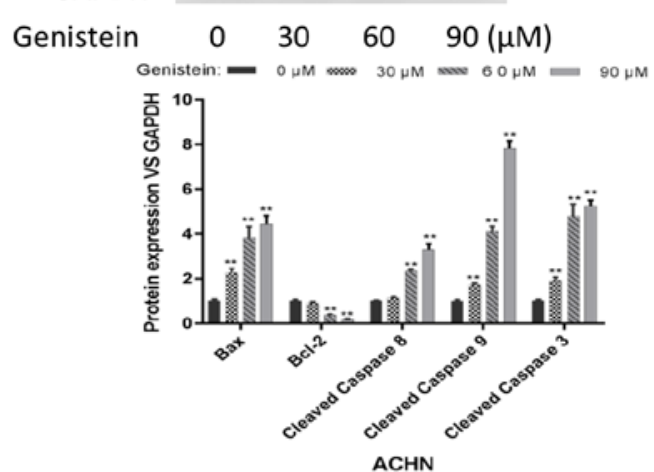

D

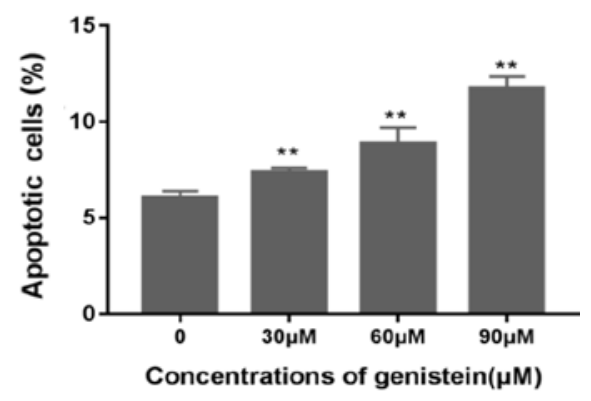

Figure 3. Genistein inhibits the proliferation and induces the apoptosis of renal CSCs. 786-O and ACHN sphere-forming cells were treated with different concentrations of genistein $(0,30,60$ and $90 \mu \mathrm{M})$ for 5 days. Western blotting was used to analyze the expression levels of various (A) proliferation-associated (PCNA and cyclin D1) and (B) apoptosis-associated (Bcl-2, Bax, cleaved caspase 8, cleaved caspase 9 and cleaved caspase 3) proteins. Apoptotic populations among ACHN sphere-forming cells were detected using flow cytometry. (C) Representative images. (D) Percentage of apoptotic cells among ACHN sphere-forming cells. Data are presented as the mean \pm standard deviation from three independent experiments. ${ }^{*} \mathrm{P}<0.05,{ }^{* *} \mathrm{P}<0.01$ vs. genistein $0 \mu \mathrm{M}$. CSC, cancer stem cell; PCNA, proliferating cell nuclear antigen.

Genistein inhibits the proliferation and induces the apoptosis of renal CSCs. Furthermore, the effects of genistein on cell proliferation and apoptosis were investigated in the present study. As presented in Fig. 3A, the expression levels of proliferation-associated proteins, including PCNA and cyclin D1, were markedly downregulated in the 786-O and 
A

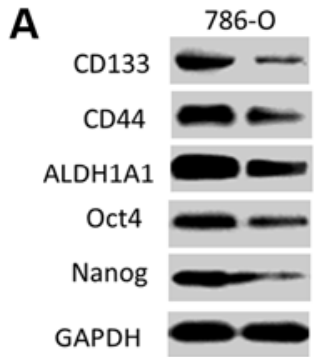

Vismodegib $0 \quad 15(\mu \mathrm{M})$

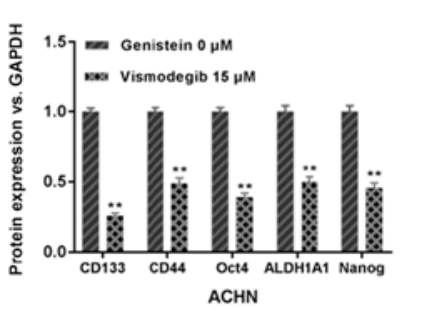

C
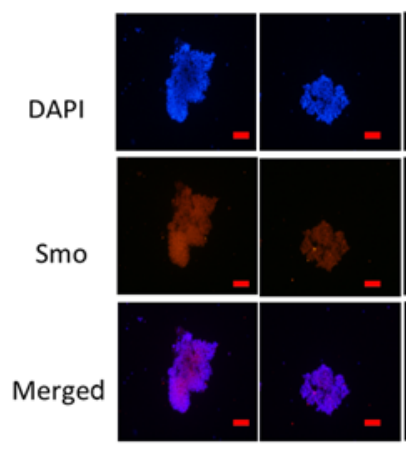

$\underline{0}$

$0 \quad 30 \mu \mathrm{M}$

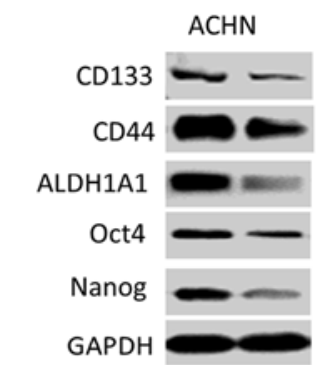

Vismodegib $015(\mu \mathrm{M})$

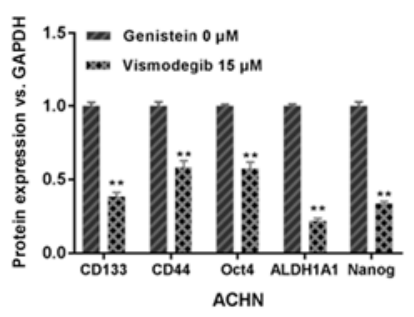

ACHN
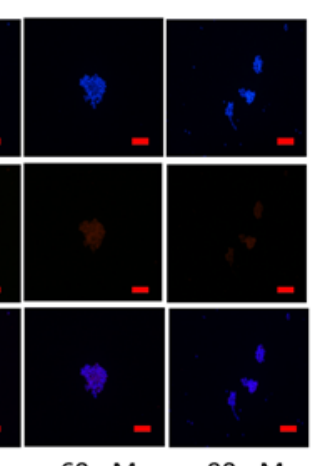

Genistein

D
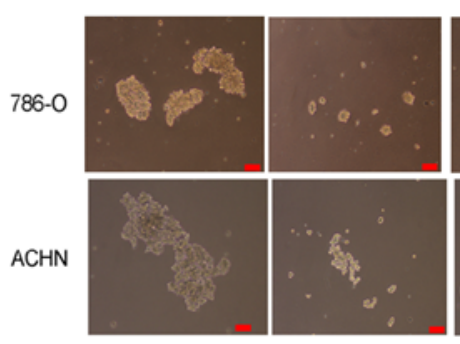

$90 \mu \mathrm{M}$ genistein

$1 \mu \mathrm{M}$ purmorphamine
$+$

$-$

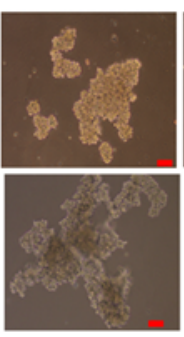

$+$
B
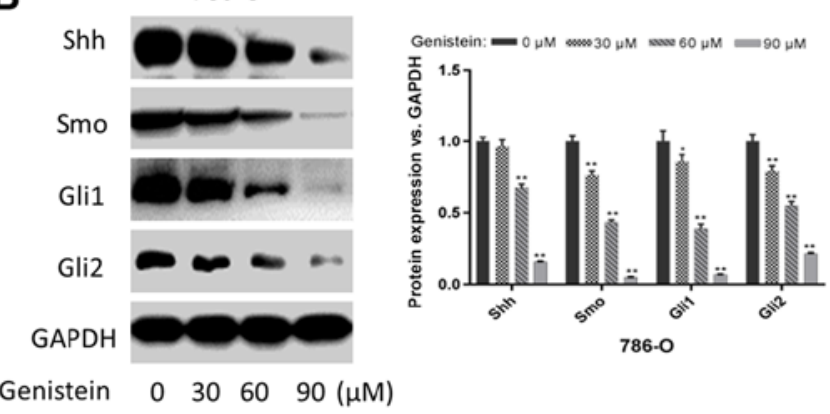

Genistein $\quad 0 \quad 30 \quad 60 \quad 90(\mu \mathrm{M})$

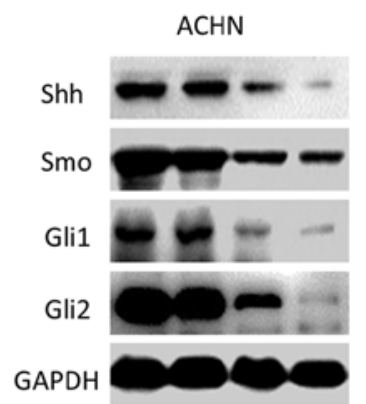

Genistein $0 \quad 30 \quad 60 \quad 90(\mu \mathrm{M})$
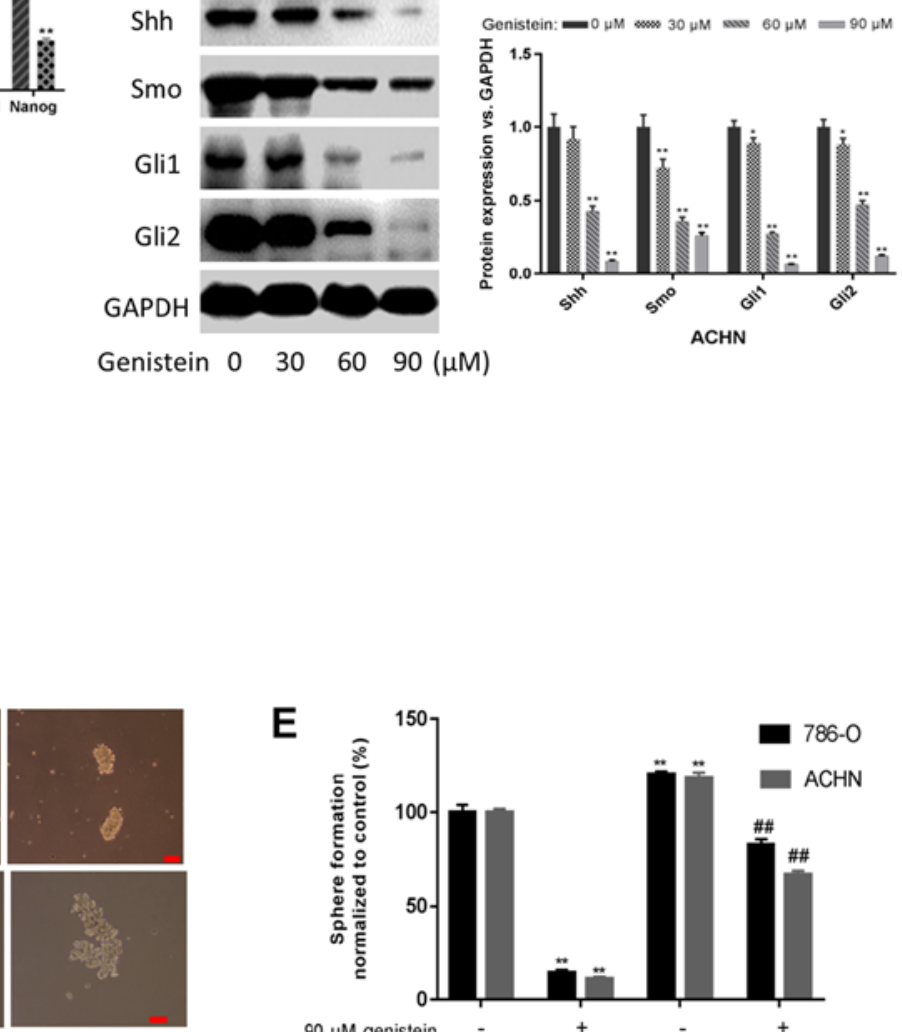

$+$
E

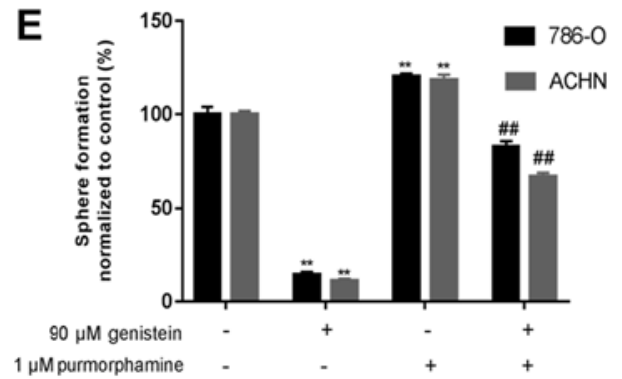

$90 \mu \mathrm{M}$ genistein

Figure 4. Genistein blocks the activity of the Shh pathway. (A) 786-O and ACHN sphere-forming cells were treated with the Smo inhibitor vismodegib (15 $\mu \mathrm{M}$ ) for 5 days, and the expression levels of renal CSC markers were assessed by western blotting. (B) 786-O and ACHN sphere-forming cells were treated with different concentrations of genistein $(0,30,60$ and $90 \mu \mathrm{M})$ for 5 days. The expression levels of critical components of the Shh pathway were measured by western blotting. (C) Immunofluorescence staining images of 786-O tumor spheres were captured to determine Smo expression. Scale bar, $100 \mu \mathrm{m}$. (D) 786-O and ACHN sphere-forming cells were treated with $90 \mu \mathrm{M}$ genistein in the presence or absence of $1 \mu \mathrm{M}$ purmorphamine for 5 days. Representative images of sphere-forming cells. Scale bar, $100 \mu \mathrm{m}$. (E) Numbers of sphere-forming cells were counted and normalized to the control group (genistein $0 \mu \mathrm{M}$ and purmorphamine $0 \mu \mathrm{M}) .{ }^{*} \mathrm{P}<0.05,{ }^{* *} \mathrm{P}<0.01$ vs. genistein $0 \mu \mathrm{M} .{ }^{\# \#} \mathrm{P}<0.01$ vs. genistein $90 \mu \mathrm{M}$. ALDH1A1, aldehyde dehydrogenase 1 family member A1; CSC, cancer stem cell; Gli, glioma-associated oncogene; Shh, sonic hedgehog; Smo, smoothened.

ACHN sphere-forming cells following genistein treatment. Additionally, the expression level of the anti-apoptotic protein Bcl-2 was decreased, while the expression levels of the pro-apoptotic proteins Bax, cleaved caspase 8, cleaved caspase 9 and cleaved caspase 3 were markedly upregulated following genistein-treatment (Fig. 3B). In addition, FCM indicated that genistein could significantly induce apoptosis in $\mathrm{ACHN}$ sphere-forming cells (Fig. 3C and D). These results revealed that genistein could inhibit the proliferation and induce the apoptosis of renal CSCs.
Genistein diminishes renal CSC characteristics by suppressing the Shh pathway. The Shh pathway is understood to be an important regulator of renal CSCs (28-30). In the present study, it was demonstrated that sphere-forming cells treated with $15 \mu \mathrm{M}$ vismodegib for 5 days, a Smo inhibitor that suppressed Shh activation, exhibited downregulated expression levels of renal CSC markers (Fig. 4A). Additionally, the present study investigated whether genistein could inhibit the Shh pathway in renal CSCs. As presented in Fig. 4B, genistein-treatment resulted in markedly decreased expression 
A

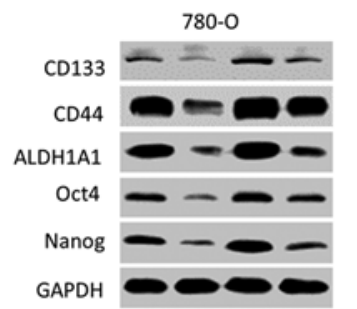

$90 \mu \mathrm{M}$ genistein $1 \mu \mathrm{M}$ purmorphamine

B
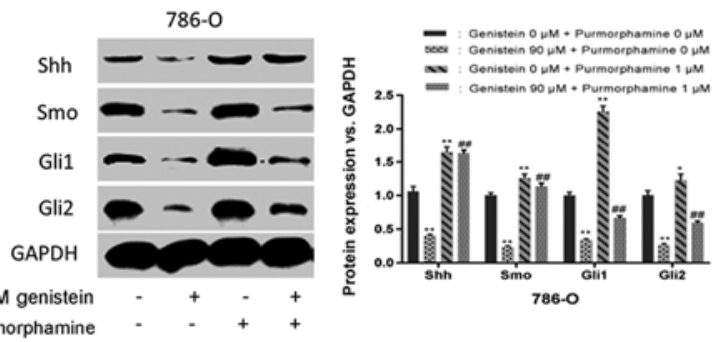

$1 \mu \mathrm{M}$ purmorphamine
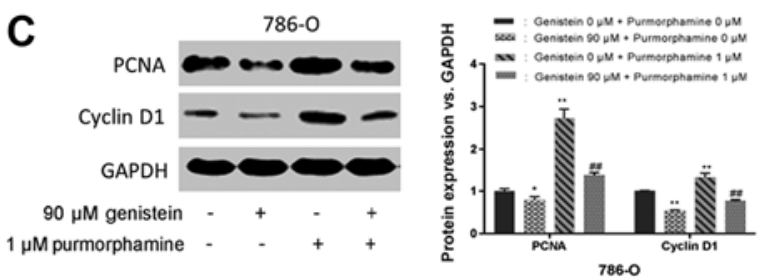

D
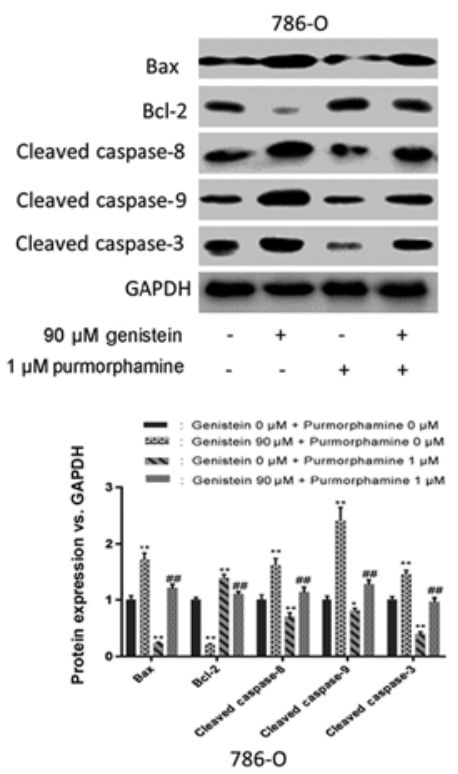
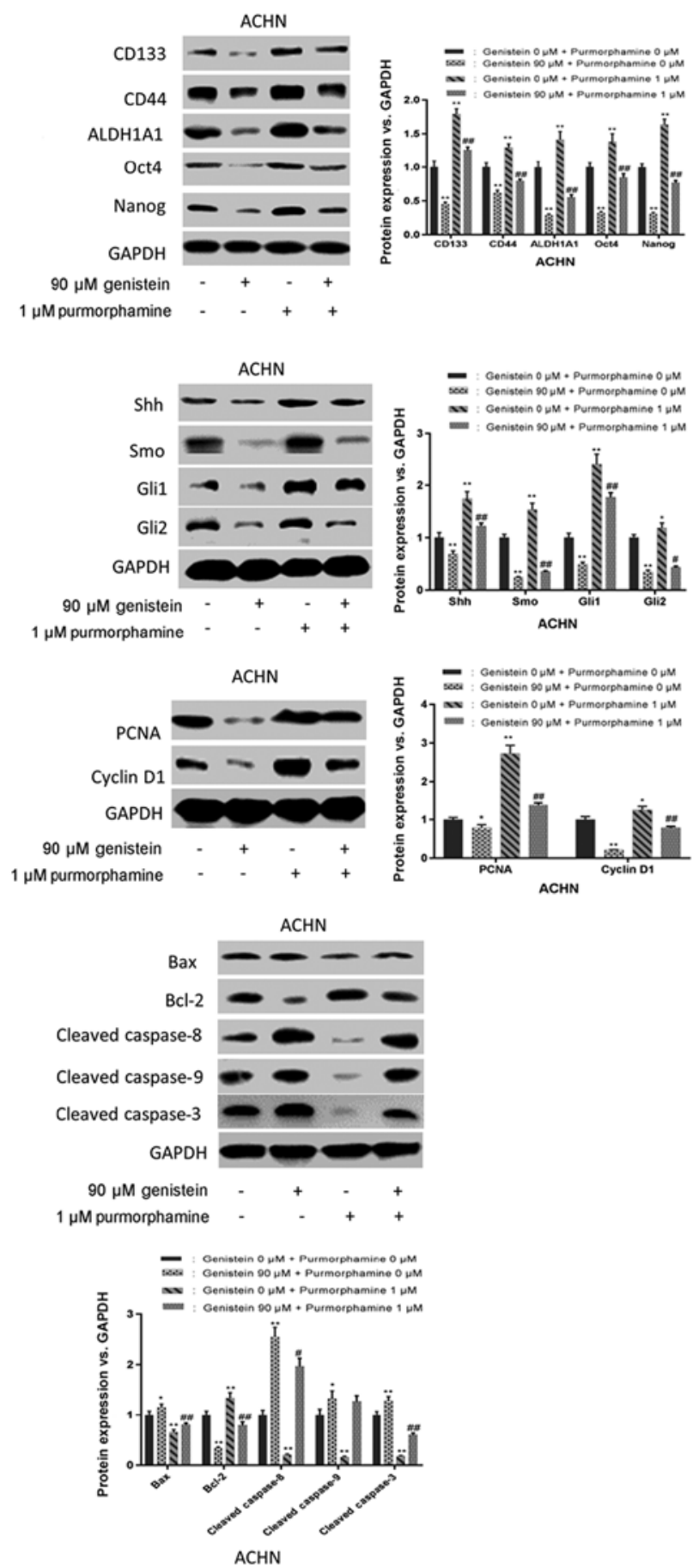

Figure 5. Genistein diminishes renal CSC characteristics by suppressing the Shh pathway. 786 -O and ACHN sphere-forming cells were treated with $90 \mu \mathrm{M}$ genistein in the presence or absence of $1 \mu \mathrm{M}$ purmorphamine for 5 days. (A) Western blot analysis of renal CSC markers. (B) Western blot analysis of the critical components of the Shh pathway. Western blotting was used to analyze the expression levels of (C) proliferation-associated proteins (PCNA and cyclin D1) and (D) apoptosis-associated proteins (Bcl-2, Bax, cleaved caspase 8 , cleaved caspase 9 and cleaved caspase 3 ). ${ }^{*} \mathrm{P}<0.05$, ${ }^{* *} \mathrm{P}<0.01 \mathrm{vs}$. genistein $0 \mu \mathrm{M}$. ${ }^{\#} \mathrm{P}<0.05,{ }^{\#} \mathrm{P}<0.01$ vs. genistein $90 \mu \mathrm{M}$. ALDH1A1, aldehyde dehydrogenase 1 family member A1; CSC, cancer stem cell; Gli, glioma-associated oncogene; PCNA, proliferating cell nuclear antigen; Shh, sonic hedgehog; Smo, smoothened.

levels of the Shh pathway-associated proteins in 786-O and ACHN sphere-forming cells. Furthermore, immunofluorescent staining indicated that the number of Smo-positive 786-O sphere-forming cells decreased following genistein-treatment in a dose-dependent manner (Fig. 4C). These data indicate that genistein may inhibit the Shh pathway in renal CSCs.

In addition, purmorphamine, an activator of Smo that activates the Shh pathway, was used to further determine the role of the Shh pathway in the suppressive effect exerted by genistein on renal CSCs. The results of the present study revealed that purmorphamine could reverse the suppressive effects of genistein on sphere formation (Fig. 4D and E). Additionally, purmorphamine-treatment increased the expression levels of renal CSC markers in 786-O and ACHN sphere-forming cells and reversed the inhibitory effect of genistein on the Shh pathway (Fig. 5A and B). Furthermore, the inhibitory effects of 
genistein on cell proliferation and apoptosis-associated proteins were reversed following purmorphamine-treatment (Fig. 5C and D). In conclusion, these results indicate a suppressive effect of genistein on renal CSCs via the inhibition of the Shh pathway.

\section{Discussion}

It has been demonstrated that CSCs serve a vital role in cancer development, progression and drug resistance. The Shh signaling pathway has been implicated in maintaining the pluripotency of CSCs. Genistein, a major isoflavone component that is isolated from soybeans and soy products, has been reported to possess anticancer activity (31). The results of the present study suggested that genistein may inhibit the activities of renal CSCs by suppressing the Shh signaling pathway.

The formation of 3D spheres under non-adherent and serum-free conditions is considered to be one of the major characteristics of CSCs (32), and this trait provides a convenient and effective way to isolate and enrich putative CSCs. To date, several markers have been used to distinguish renal CSCs, including CD133, CD44, ALDH1A1, Nanog and Oct4 $(6,33)$. CD133-positive progenitors contribute to tumor angiogenesis, which can notably enhance tumor development and growth when co-transplanted with renal carcinoma cells $(9,34)$. CD44-positive populations derived from 786-O, Caki-1, ACHN and HEK293T renal cancer cells have self-renewal properties and sphere formation capabilities $(35,36)$. In addition, clinical data have demonstrated that CD44 is associated with poor prognosis, cancer cell invasion and metastasis, as well as resistance to sunitinib-treatment $(37,38)$. ALDH1-positive cells are associated with higher sphere-forming ability, self-renewal ability and tumorigenicity compared with their ALDH1-negative counterparts (39). Additionally, aberrant expression of Oct4 and Nanog is considered to be characteristic of the pluripotent stem cells of an embryo and embryonic stem cells, which are involved in maintaining the self-renewal ability and pluripotency of CSCs (40). In the present study, renal CSCs were enriched from the adherent renal cancer cell lines 786-O and ACHN, which exhibited sphere formation capabilities when cultured under SFM conditions. Additionally, the results of the present study indicated that sphere-forming cells cultured under SFM conditions exhibited markedly elevated expression levels of renal CSC markers, including CD133, CD44, ALDH1A1, Oct4 and Nanog. An increasing amount of evidence has suggested that the quiescent stem-like populations may contribute to the formation of CSCs $(41,42)$. In line with the aforementioned findings, the present study also revealed that cells cultured under SFM conditions were more frequently arrested at the $G_{0} / G_{1}$ phase compared with the adherent cells cultured under SSM conditions. These results illustrated the CSC characteristics of these cells when cultured in SFM.

Genistein, a predominant isoflavone found in soybeans, has multiple anticancer effects in various different types of cancer, including lung, colon, head and neck squamous cell carcinoma, and hepatocellular carcinoma (21,43-45). A previous epidemiological study based on observations made in Asian countries, including China, demonstrated that the incidence rates of breast and prostate cancer are lower than those in the USA and Europe, where diets are lower in soy products (46). Accumulating evidence suggests that genistein exhibits anticarcinogenic effects on CSCs in vivo and in vitro, including in prostate (27), gastric (20) and breast cancer (19). In line with the aforementioned studies, the results of the present study suggested that genistein could efficiently diminish the activity of renal CSCs by repressing tumor sphere formation, downregulating the expression levels of renal CSC markers, and inhibiting the proliferation and inducing the apoptosis of renal CSCs.

The Shh signaling pathway is a major regulator of cell differentiation, cell proliferation and tissue polarity (47). To date, a large amount of evidence has been accumulated that supports the view that the aberrant activation of Shh signaling is involved in tumorigenesis, tumor progression and therapeutic response in several types of cancer, including medulloblastoma, malignant glioma and leukemia, as well as lung, pancreatic, breast and renal cancer $(48,49)$. Behnsawy et al $(30)$ reported that treatment with Shh recombinant, the Shh signaling stimulator, could enhance RCC cell proliferation, whereas treatment with cyclopamine, a Smo inhibitor, could inhibit tumor growth. Qian et al (29) demonstrated that Shh signaling was involved in the stimulation of renal CSC pluripotency, induced by cigarette smoking. Therefore, targeting of the Shh pathway with phytochemicals may provide a potential strategy for intervention in renal cancer. In the present study, genistein could inhibit the activation of the Shh pathways in renal CSCs by downregulating the levels of Shh, Smo, Gli1 and Gli2. By contrast, the purmorphamine-triggered activation of the Shh pathway may abolish the inhibitory effects of genistein on tumor sphere formation, CSC marker expression, and the proliferation and apoptosis of renal CSCs. Collectively, these results demonstrated the interventional effect of genistein on renal CSCs via Shh pathway inhibition. However, the results of the present study are based on in vitro experiments, therefore further in vivo studies are required to validate the role of the Shh signaling pathway in renal CSCs inhibition by genistein. Moreover, additional in vivo studies are also warranted to explore whether genistein inhibits other renal CSC models, such as side population and chemotherapy enrichment.

In conclusion, the present study revealed that genistein exerts an interventional inhibitory effect on renal CSCs by suppressing the Shh pathway, which may provide novel insights into the molecular mechanism of renal CSCs, as well as valuable avenues for investigating potential interventional targets of genistein on renal CSCs.

\section{Acknowledgements}

Not applicable.

\section{Funding}

This study was supported by the Natural Science at Higher Institutions of Anhui Province (grant no. kj2018A0209) and Natural Science Foundation of Anhui Province (grant no. 1608085QH173).

\section{Availability of data and materials}

The analyzed data sets generated during the study are available from the corresponding author on reasonable request. 


\section{Authors' contributions}

DY and CZ designed the study. EL, TZ, XS, YL and HG performed the experiments. EL analyzed the data and wrote the manuscript. All authors read and approved the final manuscript for publication.

\section{Ethics approval and consent to participate}

Not applicable.

\section{Patient consent for publication}

Not applicable.

\section{Competing interests}

The authors declare that they have no competing interests.

\section{References}

1. Znaor A, Lortet-Tieulent J, Laversanne M, Jemal A and Bray F International variations and trends in renal cell carcinoma incidence and mortality. Eur Urol 67: 519-530, 2015.

2. Siegel RL, Miller KD and Jemal A: Cancer statistics, 2015. CA Cancer J Clin 65: 5-29, 2015.

3. Reya T, Morrison SJ, Clarke MF and Weissman IL: Stem cells, cancer, and cancer stem cells. Nature 414: 105-111, 2001.

4. Ciardiello C, Leone A and Budillon A: The crosstalk between cancer stem cells and microenvironment is critical for solid tumor progression: The significant contribution of extracellular vesicles. Stem Cells Int 2018: 6392198, 2018.

5. Prager BC, Xie Q, Bao S and Rich JN: Cancer stem cells: The architects of the tumor ecosystem. Cell Stem Cell 24: 41-53, 2019

6. Lucarelli G, Galleggiante V, Rutigliano M, Vavallo A, Ditonno P and Battaglia M: Isolation and characterization of cancer stem cells in renal cell carcinoma. Urologia 82: 46-53, 2015.

7. Jiao X, Rizvanov AA, Cristofanilli M, Miftakhova RR and Pestell RG: Breast cancer stem cell isolation. Methods Mol Biol 1406: 121-135, 2016.

8. Jensen SS, Meyer M, Petterson SA, Halle B, Rosager AM, Aaberg-Jessen C, Thomassen M, Burton M, Kruse TA and Kristensen BW: Establishment and characterization of a tumor stem cell-based glioblastoma invasion model.PLoS One 11: e0159746, 2016

9. Bussolati B, Bruno S, Grange C, Ferrando U and Camussi G: Identification of a tumor-initiating stem cell population in human renal carcinomas. FASEB J 22: 3696-3705, 2008.

10. Zhong Y, Guan K, Guo S, Zhou C, Wang D, Ma W, Zhang Y, Li C and Zhang S: Spheres derived from the human SK-RC-42 renal cell carcinoma cell line are enriched in cancer stem cells. Cancer Lett 299: 150-160, 2010.

11. Huang B, Huang YJ, Yao ZJ, Chen X, Guo SJ, Mao XP, Wang DH, Chen JX and Qiu SP: Cancer stem cell-like side population cells in clear cell renal cell carcinoma cell line 769P. PLoS One 8: e68293, 2013.

12. Yang L, Xie G, Fan Q and Xie J: Activation of the hedgehog-signaling pathway in human cancer and the clinical implications. Oncogene 29: 469-481, 2010.

13. Ruch JM and Kim EJ: Hedgehog signaling pathway and cancer therapeutics: Progress to date. Drugs 73: 613-623, 2013.

14. Gorojankina T: Hedgehog signaling pathway: A novel model and molecular mechanisms of signal transduction. Cell Mol Life Sci 73: 1317-1332, 2016

15. Ruiz i Altaba A, Mas C and Stecca B: The Gli code: An information nexus regulating cell fate, stemness and cancer. Trends Cell Biol 17: 438-447, 2007.

16. Chen Y, Wang XQ, Zhang Q, Zhu JY, Li Y, Xie CF, Li XT, Wu JS, Geng SS, Zhong CY and Han HY: (-)-Epigallocatechin-3-gallate inhibits colorectal cancer stem cells by suppressing Wnt/3-catenin pathway. Nutrients 9: E572, 2017.

17. Zhu J, Wang S, Chen Y, Li X, Jiang Y, Yang X, Li Y, Wang X, Meng Y, Zhu M, et al: miR-19 targeting of GSK3beta mediates sulforaphane suppression of lung cancer stem cells. J Nutr Biochem 44: 80-91, 2017.
18. Li X, Wang X, Xie C, Zhu J, Meng Y, Chen Y, Li Y, Jiang Y, Yang X, Wang S, et al: Sonic hedgehog and Wnt/beta-catenin pathways mediate curcumin inhibition of breast cancer stem cells. Anticancer Drugs 29: 208-215, 2018.

19. Fan PH, Fan SJ, Wang H, Mao J, Shi Y, Ibrahim MM, Ma W, Yu X, Hou Z, Wang B and Li L: Genistein decreases the breast cancer stem-like cell population through Hedgehog pathway. Stem Cell Res Ther 4: 146, 2013.

20. Yu D, Shin HS, Lee YS, Lee D, Kim S and Lee YC: Genistein attenuates cancer stem cell characteristics in gastric cancer through the downregulation of Glil. Oncol Rep 31: 673-678, 2014.

21. Zhang $\mathrm{Y}$ and Chen $\mathrm{H}$ : Genistein attenuates WNT signaling by up-regulating sFRP2 in a human colon cancer cell line. Exp Biol Med (Maywood) 236: 714-722, 2011

22. Antosiak A, Milowska K, Maczynska K, Rozalska S and Gabryelak T: Cytotoxic activity of genistein-8-C-glucoside form Lupinus luteus $\mathrm{L}$. and genistein against human SK-OV-3 ovarian carcinoma cell line. Med Chem Res 26: 64-73, 2017.

23. Huang W, Wan C, Luo Q, Huang Z and Luo Q: Genistein-inhibited cancer stem cell-like properties and reduced chemoresistance of gastric cancer. Int J Mol Sci 15: 3432-3443, 2014.

24. Livak KJ and Schmittgen TD: Analysis of relative gene expression data using real-time quantitative PCR and the 2(-Delta Delta C(T)) method. Methods 25: 402-408, 2001

25. House CD, Hernandez L and Annunziata CM: In vitro enrichment of ovarian cancer tumor-initiating cells. J Vis Exp: Feb 18 2015 doi: $10.3791 / 52446$.

26. Pozzi V,SartiniD, Rocchetti R, Santarelli A, RubiniC, Morganti S, Giuliante R, Calabrese S, Di Ruscio G, Orlando F, et al: Identification and characterization of cancer stem cells from head and neck squamous cell carcinoma cell lines. Cell Physiol Biochem 36: 784-798, 2015.

27. Zhang L,Li L, Jiao M, Wu D, Wu K, Li X, Zhu G, Yang L, Wang X, Hsieh JT and He D: Genistein inhibits the stemness properties of prostate cancer cells through targeting Hedgehog-Glil pathway. Cancer Lett 323: 48-57, 2012.

28. Dormoy V, Danilin S, Lindner V, Thomas L, Rothhut S, Coquard C, Helwig JJ, Jacqmin D, Lang H and Massfelder T: The sonic hedgehog signaling pathway is reactivated in human renal cell carcinoma and plays orchestral role in tumor growth. Mol Cancer 8: 123, 2009.

29. Qian W, Kong X, Zhang T, Wang D, Song J, Li Y, Li X, Geng H, Min J, Kong Q, et al: Cigarette smoke stimulates the stemness of renal cancer stem cells via Sonic Hedgehog pathway. Oncogenesis 7: 24, 2018.

30. Behnsawy HM, Shigemura K, Meligy FY, Yamamichi F, Yamashita M, Haung WC, Li X, Miyake H, Tanaka K, Kawabata M, et al: Possible role of sonic hedgehog and epithelial-mesenchymal transition in renal cell cancer progression. Korean J Urol 54: 547-554, 2013.

31. Mukund V, Mukund D, Sharma V, Mannarapu M and Alam A: Genistein: Its role in metabolic diseases and cancer. Crit Rev Oncol Hematol 119: 13-22, 2017.

32. Tirino V, Desiderio V, Paino F, De Rosa A, Papaccio F, La Noce M, Laino L, De Francesco F and Papaccio G: Cancer stem cells in solid tumors: An overview and new approaches for their isolation and characterization. FASEB J 27: 13-24, 2013.

33. Corro $\mathrm{C}$ and Moch $\mathrm{H}$ : Biomarker discovery for renal cancer stem cells. J Pathol Clin Res 4: 3-18, 2018.

34. Park EK, Lee JC, Park JW, Bang SY, Yi SA, Kim BK, Park JH, Kwon SH, You JS, Nam SW, et al: Transcriptional repression of cancer stem cell marker CD133 by tumor suppressor p53. Cell Death Dis 6: e1964, 2015.

35. Lu J, Cui Y, Zhu J, He J, Zhou G and Yue Z: Biological characteristics of Rh123 $3^{\text {high }}$ stem-like cells in a side population of 786-O renal carcinoma cells. Oncol Lett 5: 1903-1908, 2013.

36. Debeb BG, Zhang X, Krishnamurthy S, Gao H, Cohen E, Li L, Rodriguez AA, Landis MD, Lucci A, Ueno NT, et al: Characterizing cancer cells with cancer stem cell-like features in 293T human embryonic kidney cells. Mol Cancer 9: 180, 2010.

37. Lichner Z, Saleh C, Subramaniam V, Seivwright A, Prud'homme GJ and Yousef GM: miR-17 inhibition enhances the formation of kidney cancer spheres with stem cell/ tumor initiating cell properties. Oncotarget 6: 5567-5581, 2015.

38. Mikami S, Mizuno R, Kosaka T, Saya H, Oya M and Okada Y: Expression of TNF- $\alpha$ and CD44 is implicated in poor prognosis, cancer cell invasion, metastasis and resistance to the sunitinib treatment in clear cell renal cell carcinomas. Int J Cancer 136: $1504-1514,2015$ 
39. Ueda K, Ogasawara S, Akiba J, Nakayama M, Todoroki K Ueda K, Sanada S, Suekane S, Noguchi M, Matsuoka K and Yano H: Aldehyde dehydrogenase 1 identifies cells with cancer stem cell-like properties in a human renal cell carcinoma cell line. PLoS One 8: e75463, 2013.

40. Khan MI, Czarnecka AM, Helbrecht I, Bartnik E, Lian F and Szczylik C: Current approaches in identification and isolation of human renal cell carcinoma cancer stem cells. Stem Cell Res Ther 6: 178, 2015.

41. Wu FH, Mu L, Li XL, Hu YB, Liu H, Han LT and Gong JP. Characterization and functional analysis of a slow-cycling subpopulation in colorectal cancer enriched by cell cycle inducer combined chemotherapy. Oncotarget 8: 78466-78479, 2017.

42. Giancotti FG: Mechanisms governing metastatic dormancy and reactivation. Cell 155: 750-764, 2013.

43. Tian T, Li J, Li B, Wang Y, Li M, Ma D and Wang X: Genistein exhibits anti-cancer effects via down-regulating FoxM1 in H446 small-cell lung cancer cells. Tumour Biol 35: 4137-4145, 2014.

44. Li S, Li J, Dai W, Zhang Q, Feng J, Wu L, Liu T, Yu Q, Xu S, Wang W, et al: Genistein suppresses aerobic glycolysis and induces hepatocellular carcinoma cell death. Br J Cancer 117: 1518-1528, 2017.

45. Ardito F, Di Gioia G, Pellegrino MR and Muzio LL: Genistein as a potential anticancer agent against head and neck squamous cell carcinoma. Curr Top Med Chem 18: 174-181, 2018.
46. Spagnuolo C, Russo GL, Orhan IE, Habtemariam S, Daglia M, Sureda A, Nabavi SF, Devi KP, Loizzo MR, Tundis R and Nabavi SM: Genistein and cancer: Current status, challenges, and future directions. Adv Nutr 6: 408-419, 2015.

47. Ruiz i Altaba A: Hedgehog signaling and the Gli code in stem cells, cancer, and metastases. Sci Signal 4: pt9, 2011.

48. Rimkus TK, Carpenter RL, Qasem S, Chan M and Lo HW: Targeting the sonic Hedgehog signaling pathway: Review of smoothened and GLI inhibitors. Cancers (Basel) 8: E22, 2016.

49. D'Amato C, Rosa R, Marciano R, D'Amato V, Formisano L, Nappi L, Raimondo L, Di Mauro C, Servetto A, Fulciniti F, et al: Inhibition of Hedgehog signalling by NVP-LDE225 (Erismodegib) interferes with growth and invasion of human renal cell carcinoma cells. Brit J Cancer 111: 1168-1179, 2014.

This work is licensed under a Creative Commons Attribution-NonCommercial-NoDerivatives 4.0 International (CC BY-NC-ND 4.0) License. 